\title{
THE PATHOGENESIS OF IDIOPATHIC SCOLIOSIS
}

\author{
BIPLANAR SPINAL ASYMMETRY \\ R. A. DICKSON, J. O. LAWTON, I. A. ARCHER, W. P. BUTT \\ From St James's University Hospital, Leeds
}

\begin{abstract}
A clinical, cadaveric, biomechanical and radiological investigation of the pathogenesis of idiopathic scoliosis indicates that biplanar asymmetry is the essential lesion. Many normal children have coronal plane asymmetry (an inconsequential lateral curvature of the spine), and certainly all have vertebral body asymmetry in the transverse plane, but when median plane asymmetry (flattening or more usually reversal of the normal thoracic kyphosis at the apex of the scoliosis) is superimposed during growth, a progressive idiopathic scoliosis occurs. Idiopathic kyphoscoliosis cannot and does not exist, from the mildest cases in the community to the most severe cases in pathology museums. Median plane asymmetry is crucial for progression and the lateral profile of the spine must be carefully scrutinised. Increased anterior vertebral height at the apex of the curve with posterior end-plate irregularity characterises the median plane asymmetry and suggests that idiopathic scoliosis is the reverse of Scheuermann's disease.
\end{abstract}

Idiopathic scoliosis is a lateral curvature of the spine in the absence of any relevant congenital spinal anomaly or associated musculoskeletal condition. Rotation and progression potential both characterise the clinical deformity. Most workers favour a neuromuscular basis for the condition although growth and genetic factors may be important. Early promising electromyographic findings (Lerique and LeCoeur 1951) have either been invalidated (Alexander and Season 1978) or shown to be secondary to the spinal deformity (Trontelj, Pečak and Dimitrijević 1979). In addition, structural abnormalities of the spinal musculature (Kaneko 1968) have also been shown to be secondary findings (Khosla et al. 1980) and equilibrial dysfunction (Yamada et al. 1969) is more likely to be a feedback from the deformed spine (Sahlstrand and Petruson 1979). The increased prevalence of idiopathic scoliosis in families (Staub 1922) appears to reflect a growth pattern which families also share (Boas 1932).

"Normal" children have neither straight nor symmetrical spines (Dickson 1983). Fifteen per cent of children show evidence of a lateral curvature on a crude visual test and as many as 30 per cent with a more accurate screening method (Burwell et al. 1982). Indeed, anatomists two centuries ago clearly demonstrated that everyone had a scoliosis, albeit of small magnitude (Sabatier 1777). However, only two to five per thousand

R. A. Dickson, MA, ChM, FRCS, FRCS Ed, Professor and Head of the Department of Orthopaedic Surgery

J. O. Lawton, MA, FRCS. Tutor in Orthopaedic Surgery

I. A. Archer, FRCS, Lecturer in Orthopaedic Surgery

W. P. Butt, FRCR, FRCP(C), FACR(Hon), Consultant Radiologist

St James`s University Hospital, Leeds LS9 7TF, England.

Requests for reprints should be sent to Professor R. A. Dickson.

(C) 1984 British Editorial Society of Bone and Joint Surgery $0301-620 \mathrm{X} / 84 / 1002 \$ 2.00$ have curves measuring 20 degrees or more and therefore clearly another important factor or factors must exist before an unimportant curvature becomes a progressive rotational idiopathic scoliosis.

It has long been known that patients with idiopathic thoracic curves have median (sagittal) plane asymmetry in the nature of a lordosis at the curve apex (Adams 1865) and that the thoracic kyphosis in normal children is considerably reduced in early adolescence (Willner 1981). Furthermore, a combination of lordosis and asymmetry of the spine in the coronal plane has recently been shown to produce "idiopathic" scoliosis experimentally (Dickson et al. 1983). This present clinical, cadaveric, biomechanical and radiological study indicates that biplanar spinal asymmetry is the essential lesion of idiopathic scoliosis and adequately explains its clinical behaviour.

\section{MATERIALS AND METHODS}

Clinical investigation. Seventy patients with idiopathic thoracic scoliosis were studied: there were 55 females and 15 males and their mean age was 14.2 years (range 7 to 26). All 70 were studied on presentation, and anteroposterior and lateral radiographs were taken before the spinal shape could have been affected by any form of treatment. The anteroposterior radiographs were AP projections of the patient and not of the apex of the rotated curve (Stagnara et al. 1975). Fifty-five lateral films also were laterals of the patient, but the 15 most recent lateral films were true laterals of the apex of the rotated curve. From the anteroposterior radiographs the magnitude of the scoliotic curve was measured using Whittle's adaptation of Cobb's method (Whittle and Evans 1979); and from the lateral radiographs both the 
angle of the overall thoracic kyphosis and the angle subtended by the vertebrae at the apex of the scoliosis were similarly recorded. Five children with idiopathic scoliosis were also subjected to computerised axial tomography in order to determine the degree and pattern of rotation of their curves.

Cadaveric analysis. Eleven cadaveric spines with idiopathic scoliosis were borrowed from the Museum of the Royal College of Surgeons in Edinburgh by courtesy of Professor D. C. Meekie. Four were natural specimens and in seven the axial skeleton was reconstructed using artificial material for discs and ligaments. All were subjected to standardised radiography and photography. Anteroposterior and lateral films and photographs were taken of the specimens and then of the apex of the curve. From these films the angles of the scoliosis and the lateral profile of the spine were measured. The four natural specimens were also subjected to computerised tomography in the transverse axial and longitudinal planes.

Biomechanical studies. A simplified theoretical model of a spine with biplanar asymmetry was constructed (Fig. 1), with the important forces and their directions inserted. Then, using fresh natural spines, removed at necropsy from 1400-gram New Zealand white rabbits, the behav-

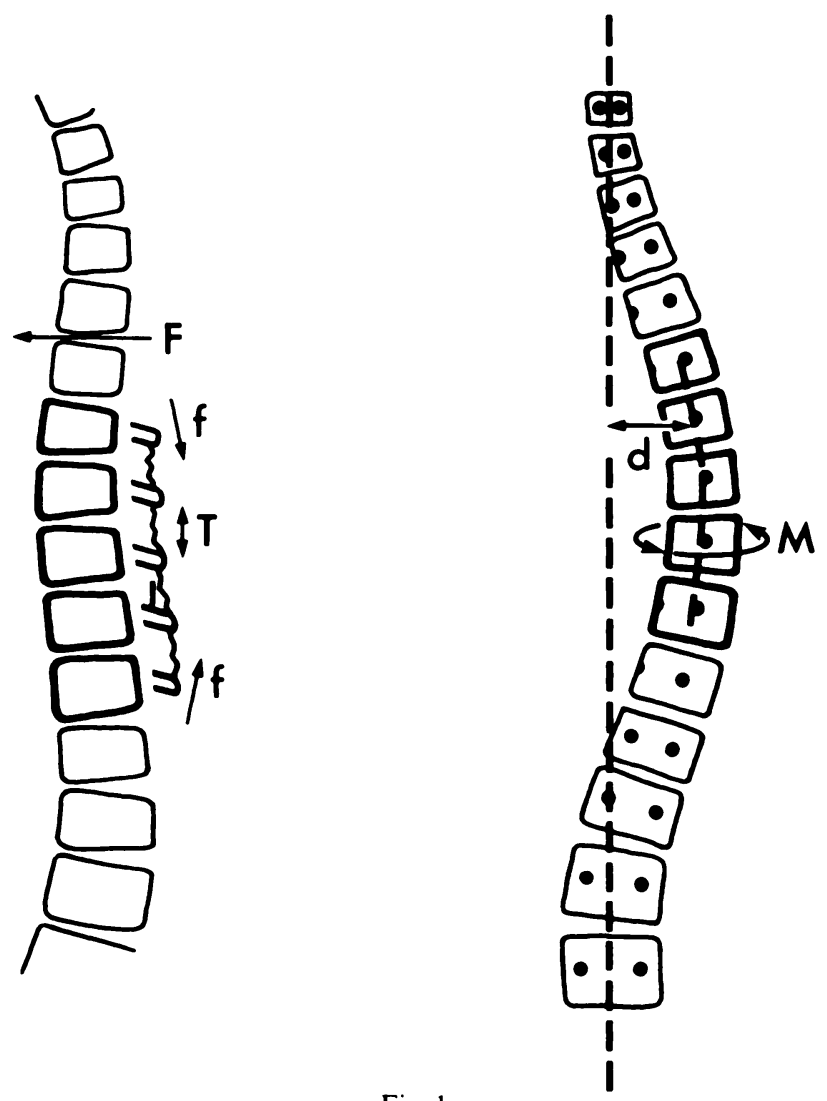

Fig. 1

Simplified theoretical model of biplanar spinal asymmetry. Lateral profile with lower thoracic lordosis (left); anteroposterior view of coronal plane asymmetry (right). $M \times f . d$, where $F=$ force of forward flexion: $T=$ tightening of posterior structures; $f=$ reactive force: $d=$ distance of coronal plane asymmetry from midline; and $M=$ spinning moment.

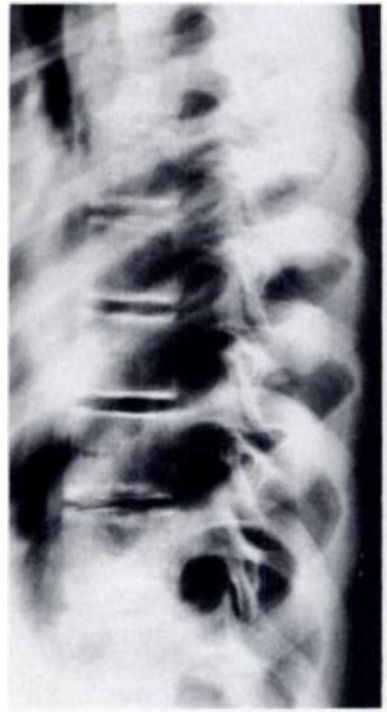

Fig. 2

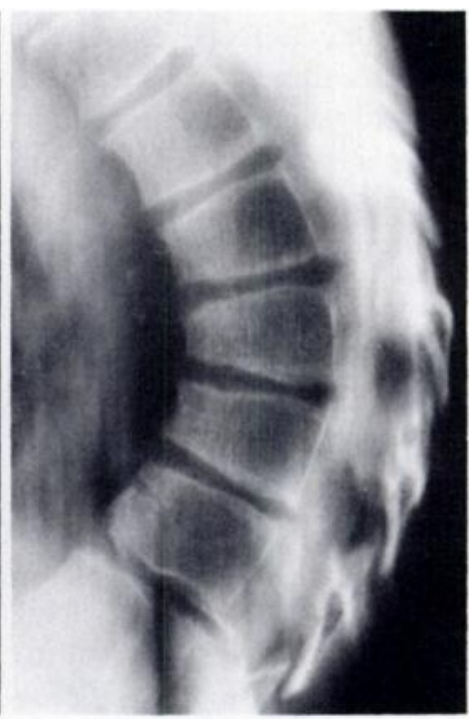

Fig. 3
Figure 2-True lateral projection of the apex of an idiopathic thoracic curve. There is a mild lordosis and the apical vertebrae are distinctly wedged, the anterior vertebral height being longer than the posterior with end-plate irregularity. Figure 3--Lateral projection of the apex of a Scheuermann's kyphosis. Again there is vertebral wedging and endplate irregularity, but exactly the opposite of Figure 2: here the anterior vertebral body height is shorter than the posterior.

iour of the spine in relation to the theoretical model was investigated. Specimens were flexed forward to and beyond the limits of normal movement; then, after the creation of a short-segment biplanar asymmetry in the lower thoracic region using compression wiring of the spinous processes, forward flexion was repeated. Sample radiographs were taken through and beyond the normal limits of spinal flexion.

\section{RESULTS}

Clinical investigation. The mean Cobb angle of the scoliosis in the 70 patients was 39 degrees and the overall angle of thoracic kyphosis was 20 degrees. However, when the lateral profile at the apex of the scoliosis was measured, all showed evidence of median plane asymmetry. There was a mean lordosis of three degrees at the apex of the curve which involved only the apical two or three segments. More specifically, 75 per cent of these apical lateral profiles were lordotic, 24 per cent straight; one per cent were kyphotic, but of a radius much greater than that of the kyphosis above. There was no kyphosis below the apex, indicating that the lordotic area was an abnormal continuation upwards of the lumbar lordosis. The apical one or two vertebrae were observed to be distinctly wedged, the anterior vertebral body height being greater than the posterior height, often with endplate irregularity posteriorly (Figs 2 and 3 ).

There was a significant correlation between the Cobb angle of the scoliosis and that of the overall kyphosis $(P<0.01)$; and the apical lateral Cobb angle was significantly negatively correlated with the angle of 
overall kyphosis $(P<0.001)$. The position of the median plane asymmetry correlated with the apex of the scoliosis $(P<0.001)$ with the ninth thoracic vertebra as the mode. Computerised axial tomography demonstrated constant findings (Fig. 4). While the apical vertebrae had spun furthest from the neutral position they were least rotated one to another. Maximum intervertebral rotation occurred at the junctions of the structural curve and its upper and lower compensatory curves; this was strictly in the nature of derotation bringing the spine neutral above and below.

Cadaveric analysis. The appearance of the specimens from the front and side demonstrated a mean Cobb angle for the scoliosis of 67 degrees and a mean overall angle of kyphosis of 76 degrees. This apparent kyphosis was entirely spurious, the scoliosis itself being seen in two planes at right angles, which are neither anteroposterior nor lateral projections of the apex of the curve because in severe cases the spine is directed not only sideways but backwards in the region of the scoliosis (Figs 5 to 10).
When true anteroposterior and lateral projections of the apex were measured, the mean Cobb angle of scoliosis was increased to 90 degrees, and there was a mean lordosis at the apex measuring three degrees. Computerised axial tomography showed rotational changes similar to those of the patients. Computerised vertical tomography demonstrated that it was possible to obtain the entire specimen on one longitudinal slice measuring $12 \mathrm{~mm}$, confirming that a kyphosis did not exist (Fig. 11).

Biomechanical studies. Figure 1 shows the effect of flexion of a lordotic segment of the spine with pre-existing coronal plane asymmetry. The force of forward flexion $(F)$ produces tightening of the posterior structures $(T)$ and a reactive force $(f)$. The horizontal component of $f$ acting at a distance $(d)$ from the midline will produce a spinning moment $(M)$ with the spinous processes being drawn back to the midline. The magnitude of this spinning moment is therefore a function of the force of forward flexion and degree of biplanar asymmetry. Asymmetric vertebral shape in the transverse plane

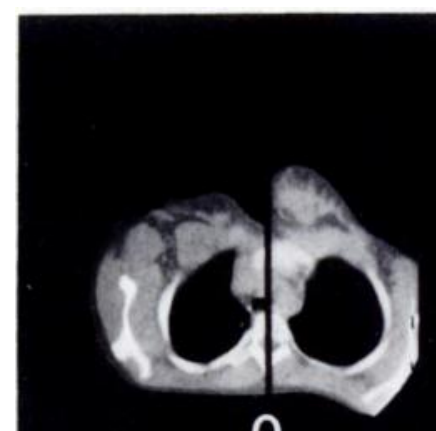

T3

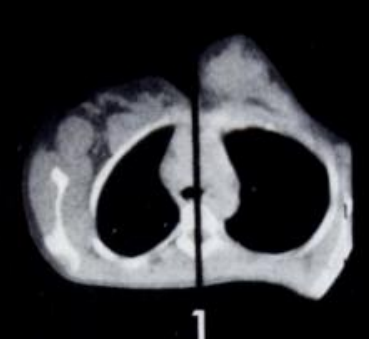

T4

1

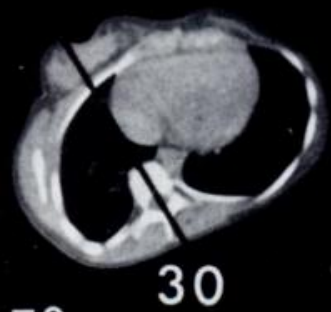

T 8

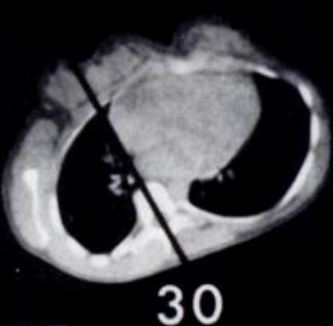

T 7
30

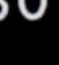

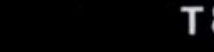

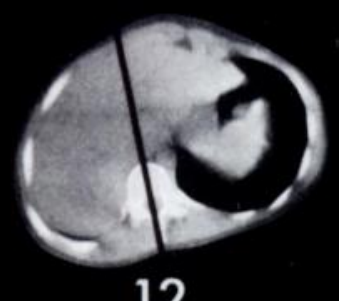

$\mathrm{T} 11$
12

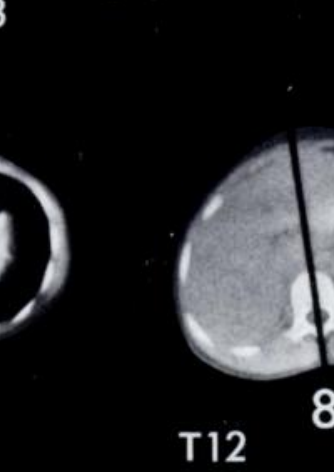

T12

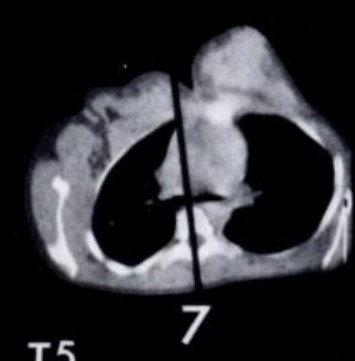

T5

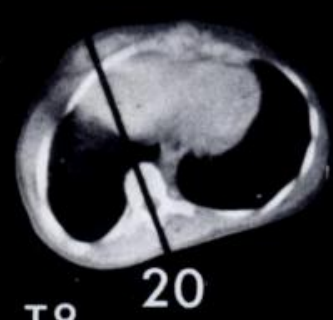

T9

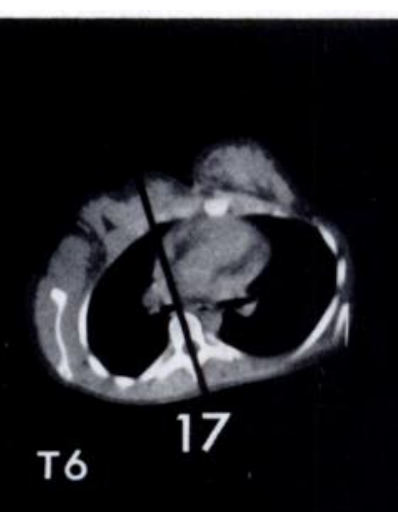

T6

.




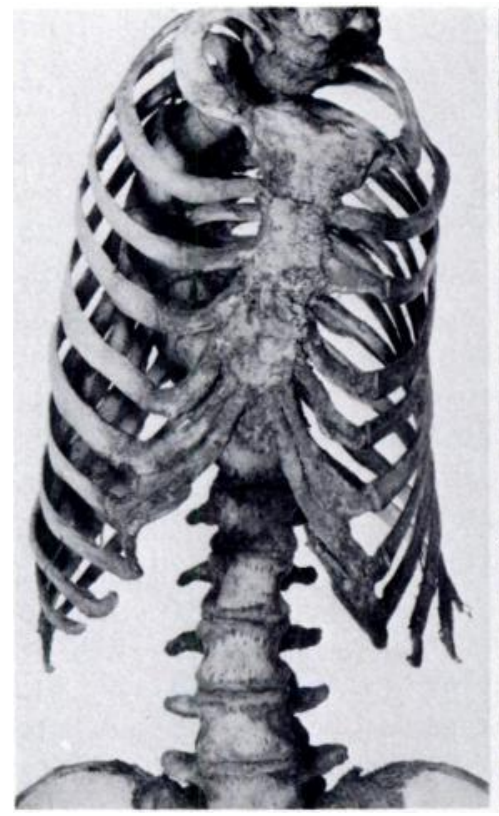

Fig. 5

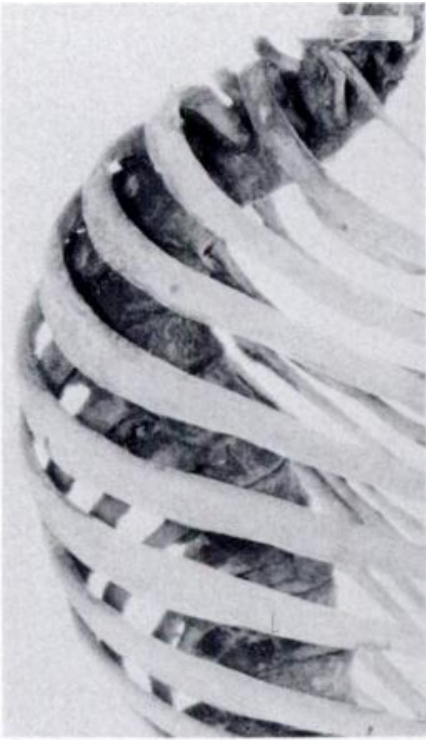

Fig. 7

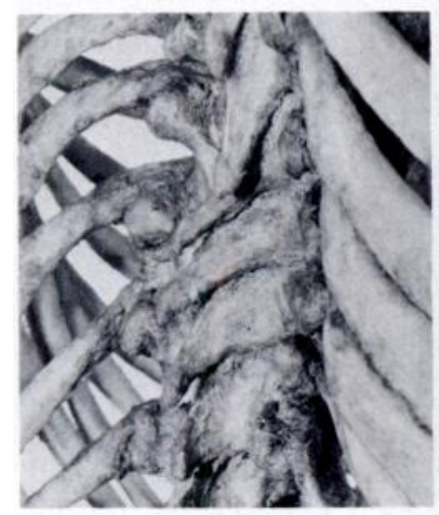

Fig. 9

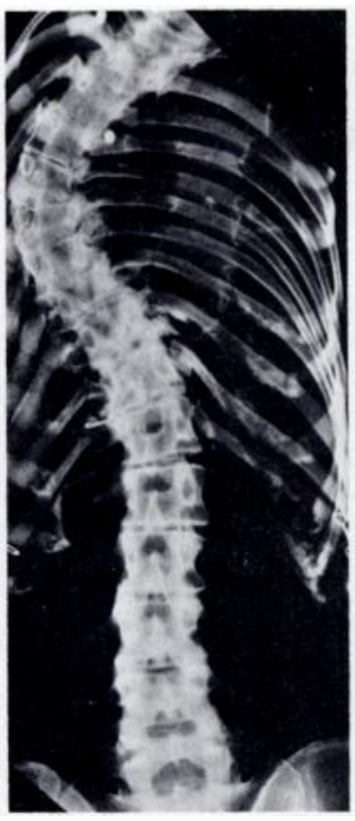

Fig. 6

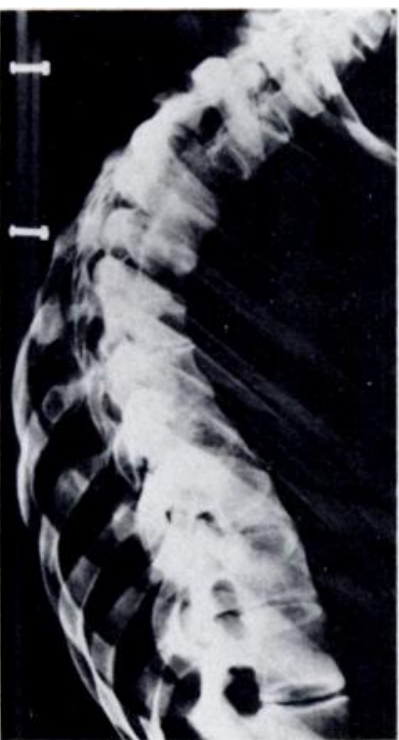

Fig. 8

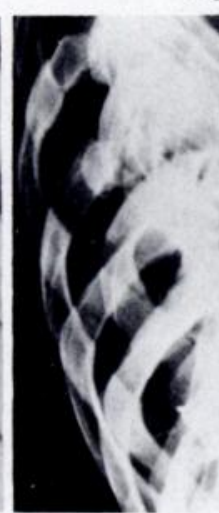

Fig. 10
Figures 5 and 6-Anteroposterior photograph and radiograph of a specimen with severe right thoracic scoliosis. Figures 7 and 8 - Lateral photograph and radiograph of the same specimen showing an apparent and spurious kyphosis. Figures 9 and $10-$ True lateral photograph and radiograph of the apex of the curve demonstrating a lordosis. would produce the same effect as coronal plane asymmetry. Median plane asymmetry does not have to be in the nature of a lordosis, as flat or slightly kyphotic segment models satisfy the rotational requirements.

Forward flexion of the rabbit thoracolumbar spine to the limits of normal movement is not coupled with any axial rotation. When specimens with biplanar asymmetry are flexed, then the relative tightening of the posterior structures (or excessive length of the anterior structures) creates a tendency for the spine to rotate, precipitated by any inherent coronal plane asymmetry in the system (Figs 12 and 13). The effect of rotation on this lordotic region is such that the vertebral bodies lie on the convexity and the posterior elements on the concavity. Excessive forward flexion of the normal spine beyond the limits of compression of the anterior structures does produce rotation but with the bodies directed to the concavity and the posterior elements to the convexity as would be expected with a rotated kyphosis.

\section{DISCUSSION}

The anatomical planes of the body are the coronal plane (dividing the body into front and back portions), the median (sagittal) plane (dividing the body into right and left halves) and the transverse or horizontal plane (any cross-section) (Brash 1951). In the median plane the spine has four symmetrical curvatures, cervical and lumbar lordoses and thoracic and sacral kyphoses. The

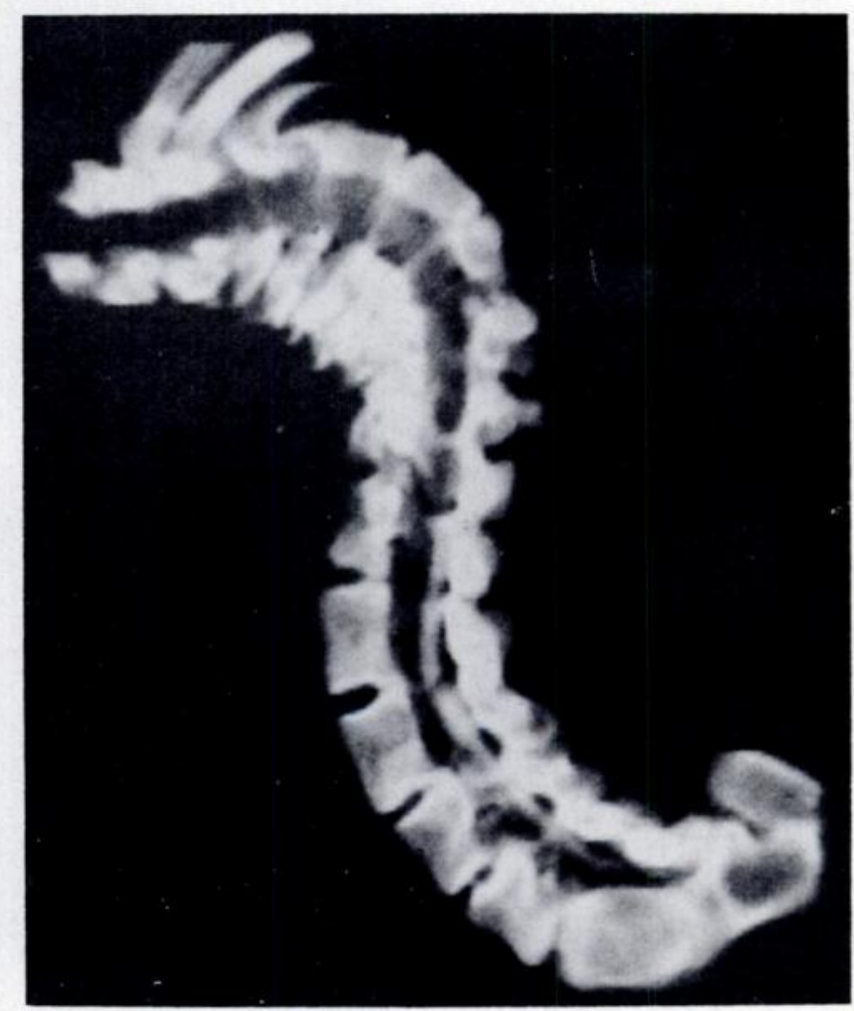

Fig. 11

Computerised vertical tomography of a cadaveric specimen with severe idiopathic scoliosis. The entire specimen is obtainable in one longitudinal slice. A kyphosis cannot exist. 
deformity of idiopathic scoliosis appears as a curvature in the coronal plane but this deformity is entirely secondary. It is the product of lordosis plus rotation as Adams stated in 1865 . Indeed this must be the case as rotation always occurs in the same direction, with the spinous processes directed towards the concavity, whereas in a rotated kyphosis the spinous processes are always directed towards the convexity (Somerville 1952).

It is a constant clinical feature in idiopathic scoliosis that the normal spinal curvatures in the median plane are altered-reduced in the thoracic region with thoracic curves. Willner (1981) measured the overall thoracic kyphosis and demonstrated statistically that patients with idiopathic thoracic scoliosis had flatter thoracic kyphoses than normal children, whose kyphoses in turn were flatter than patients with Scheuermann's disease. However, his measurements were made from the top to the bottom of the thoracic kyphosis and he did not look at the median plane in the region of the apex of the curve.
When this is scrutinised there is always evidence of a lordosis or lordotic tendency and this is clearly visible from modest scolioses to the severest specimens in pathology museums. Furthermore, it is this appearance which differentiates progressive from non-progressive scolioses detected by school screening. When true lateral projections of the apex are obtained, there is clear evidence of asymmetric vertebral growth, with anterior body height greater than posterior. The findings of computerised axial tomography indicate that it is the area of lordosis as a whole that has spun out from the neutral plane, there being much less intervertebral rotation occurring at the apex.

Importantly, spinal curvatures in the median plane change during growth and in normal children the thoracic kyphosis reduces in size from the age of 8 to 14 years, reaching a minimum at about the age of 12 . That this occurs at the same time in both boys and girls demonstrates its independence from growth velocity,

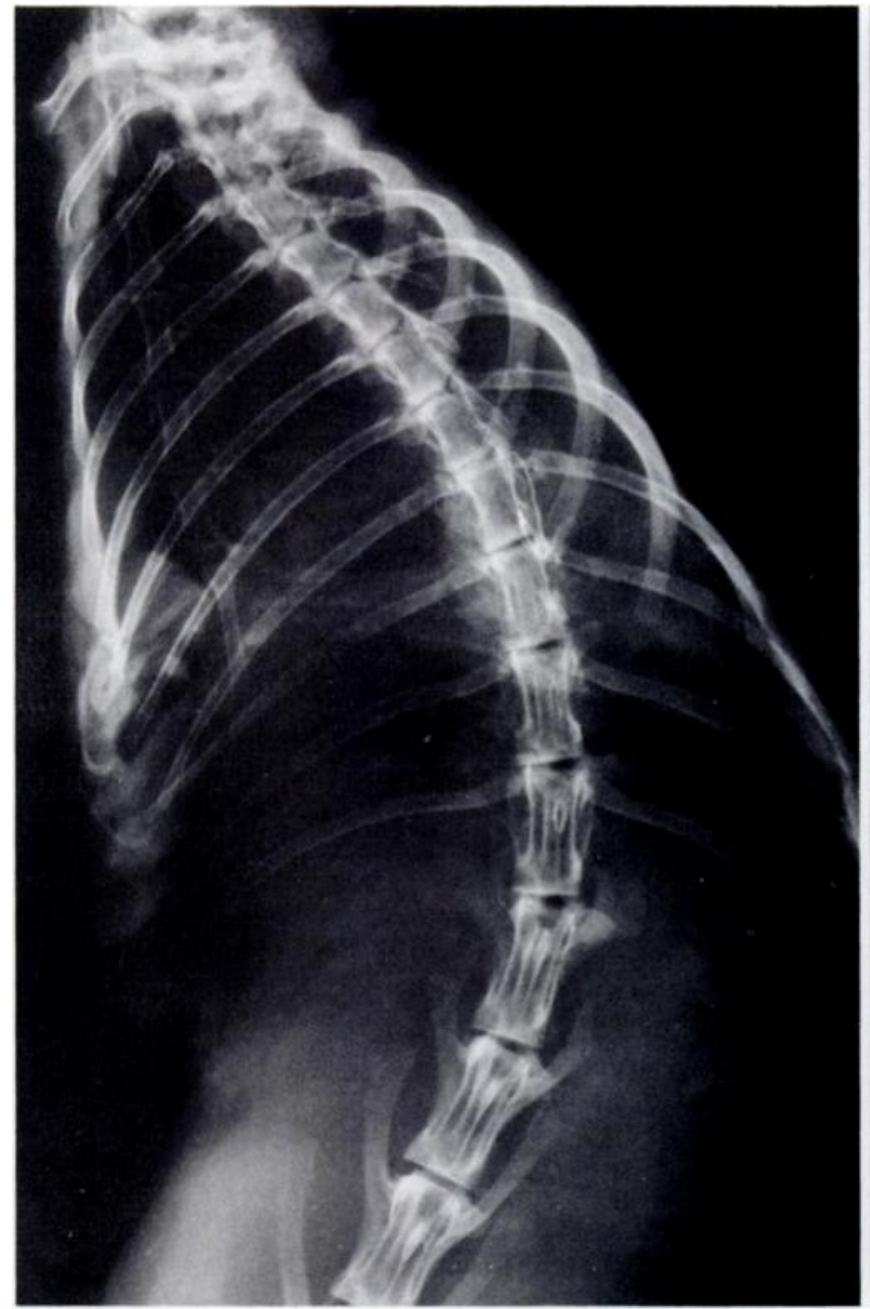

Fig. 12

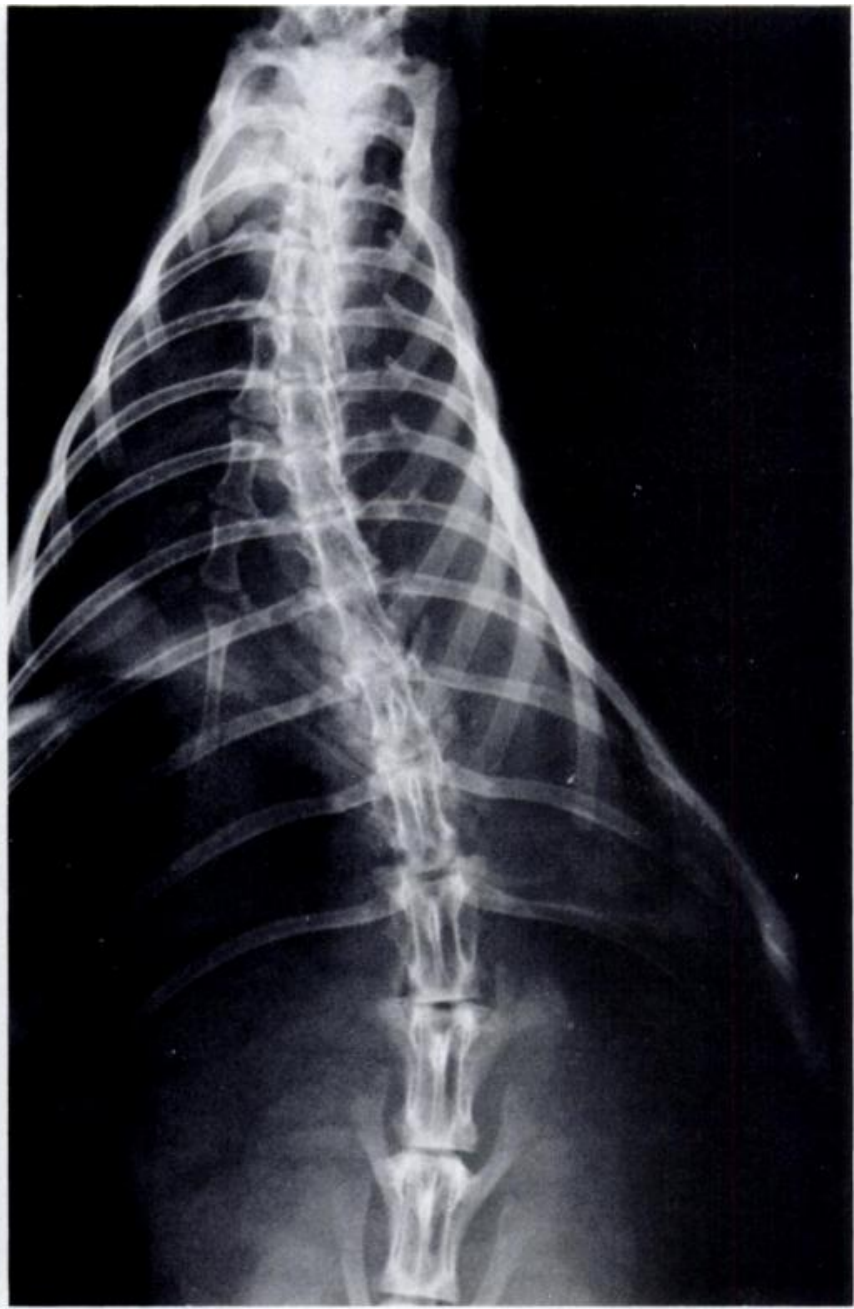

Fig. 13

Figure 12-Anteroposterior view of a fresh normal rabbit spine that has been flexed beyond the normal limits. A lateral curvature of the spine has been produced but the thoracic spinous processes are directed towards the convexity as would be expected with a rotated kyphosis. Figure 13 Anteroposterior view of a fresh rabbit spine with thoracic biplanar asymmetry which has been similarly flexed. A thoracic scoliosis has been produced but the spinous processes are directed towards the concavity. 
boys on average maturing some two years later. However, when the thoracic kyphosis is at its minimum in girls, they are going through peak adolescent growth velocity and this may explain greater progression potential in girls. When the thoracic kyphosis is at its minimum in boys their growth velocity is constant but when their thoracic kyphosis becomes maximal in later adolescence they are then going through peak adolescent growth velocity, which may explain why boys are particularly prone to developing Scheuermann's disease, the opposite median plane deformity.

Interestingly, it is during this phase of reduction in thoracic kyphosis that the incidence of scolioses detected in the community rises sharply in both boys and girls (Dickson 1983). The cadaveric analysis reinforces the need to think and see in three dimensions. Idiopathic kyphoscoliosis does not exist at any magnitude even in the most severe specimens. The spurious appearance of a kyphosis when the patient is viewed from the side is the scoliosis seen in a plane which is more an anteroposterior projection of the apex of the curve than an AP projection of the patient or specimen, compounded to a lesser extent by the deceptive rib hump. If the whole of the spinal canal can be visualised from upper cervical to lower lumbar region in one longitudinal slice, then a kyphosis cannot possibly exist.

The apical site in thoracic idiopathic scoliosis is bimodal, the great majority being apical at the T8-9 level with a small minority apical at the $\mathrm{T} 3$ level. These are important regions of the spine in both median and transverse planes. Anatomists have recorded in detail that while the thoracic spine extends from $T 1$ to $T 12$ by convention this is not anatomically so (Inkster 1951). The first two and last three thoracic vertebrae resemble typical cervical and lumbar vertebrae respectively. Typical thoracic vertebrae only extend from $\mathrm{T} 3$ to $\mathrm{T} 9$. The potential rotational instability of the cervical and lumbar lordoses is counteracted by the shape of these vertebrae in the transverse plane. The increased lateral to anteroposterior width (a prism with its base anteriorly) confers great rotational stability aided by the powerful posterior muscular, ligamentous and fascial support in the cervical and lumbar regions.

In contradistinction the heart-shaped thoracic vertebra (a prism with its apex anteriorly) is rotationally unstable and is therefore protected by the presence of a kyphosis, which places the axis of spinal rotation anterior to the vulnerably shaped bodies. In the true lateral projections of patients and specimens there was no compensatory or associated kyphosis below the area of lordosis, which was therefore a lumbar lordosis extending abnormally high. At the apex of the curve there is now a vertebra heart-shaped in the transverse plane, and computerised axial tomography confirms this, which is not protected by a kyphosis. Only a mild lordosis or lordotic tendency is sufficient to cause the spine to rotate to the side and, once the apex has rotated, the posterior part of the end-plate is relieved from direct compression. This is verified by the observation that the size of the lordosis does not correlate with the size of the scoliosis. The negative correlation with the angle of the total kyphosis shows that it is the size of the lordosis which relates to the amount of reduction of the overall kyphosis.

The concept of a short-segment lordosis being an important factor has only received sporadic support (Heuer 1927: Somerville 1952; Roaf 1966; Deane and Duthie 1973). Figure 13 clearly shows the spinning potential of a lordosis but the system would be in equilibrium even in extreme forward flexion unless there was spinal asymmetry in another plane. Biplanar asymmetry is therefore the crucial factor and such a spine will readily deform accordingly. Somerville was a pioneer in this respect and produced a progressive "idiopathic" scoliosis in three rabbits by causing a short-segment lordosis. He must, however, have inadvertently caused a few degrees of coronal plane asymmetry, as when this work was repeated by others (Wittebol 1956; Gottlieb 1957) the spine remained disappointingly straight. This is because animals, unlike so many normal children detected in the community by school screening programmes, have no recorded tendency to have a preexisting coronal plane curvature which provides rotational instability. "Idiopathic" scoliosis can only be produced in animals if asymmetry in two planes is produced at the same time (Dickson et al. 1983). The younger the patient or animal, the more serious is the progression potential because of the overall environment of growth. While the epiphyses of the long bones and pelvis are fused by the eighteenth year, the vertebral epiphyses do not do so until the twenty-fifth (Inkster 1951) and this may explain the recent finding that the majority of idiopathic curves progress until that time (Hassan and Bjerkreim 1983).

Normal spinal asymmetry also exists in the transverse plane, particularly in the thoracic region, where the thoracic vertebrae from T5 to T8 are constantly grooved on the left side by the pulsations of the descending aorta, and this is more obvious when the thoracic kyphosis is reduced, bringing spine and artery in apposition. The thoracic vertebrae are therefore asymmetric prisms and the presence of a lordosis without coronal plane asymmetry will produce rotation with the convexity to the right. The primary asymmetry is in the body, pedicle asymmetry being secondary to the scoliosis (Karaharju 1967). Indeed, a minor degree of transverse plane asymmetry may be the factor producing so much coronal plane asymmetry observed in normal children. This is reinforced by the observation that many normal children (children without a scoliosis) have a slight rib hump on the right side on forward flexion (Burwell et al. 1982). This of course is asymmetric buckling of a normal thoracic kyphosis but when there is a lordotic region in the lower thoracic spine a true rotational lordosis produces a progressive idiopathic curve. 
It is therefore the lateral profile of the spine which is the key to the understanding of progressive idiopathic deformities. Both idiopathic scoliosis and Scheuermann's disease have been shown to have a not dissimilar incidence and a familial trend (Sørensen 1964; WynneDavies 1965). As virtually all aspects of growth are governed by genetic mechanisms it may well be the lateral profile which is genetically determined. At the extremes of the spectrum of lateral profile are on the one hand those with the most pronounced median plane curvatures in whom Scheuermann's disease is the clinical manifestation, and on the other those with the flattest profile who are particularly vulnerable to developing a rotational lordosis. The flat lateral profile of patients with idiopathic scoliosis also explains the observation that these children are taller than their peers but not growing faster (Dickson and Sevitt 1982). This is more likely the effect of the lateral profile than genetic tall stature as the condition affects children of all sizes.

This concept of biplanar spinal asymmetry more than adequately explains the clinical behaviour of idiopathic scoliosis. On forward flexion the rotational prominence increases, being maximal on full flexion. The greater the flexion, the less the relatively increased anterior vertebral height at the apex can be accommodated without rotating to the side. Non-structural scolioses barely rotate because their asymmetry does not affect the lateral profile. Conservative treatment, be it brace or cast, is effective primarily in preventing spinal flexion but cannot, however, be corrective as only the status quo of the secondary deformity is preserved while the primary lordosis may in fact be increased. That brace-wearing is only at best holding and is never corrective testifies to this mode of action, but as the curve increases, so the brace is less effective as a holding device because the increasingly adverse effects of gravity cannot be attenuated merely by preventing flexion.

Underarm orthoses are effective if the apex of the curve is not above the eighth thoracic vertebra because higher curves can still flex. A crucial part of brace design is that the lumbar lordosis should be obliterated (Blount and Moe 1973) and this produces the well-recognised phenomenon of a temporary partial correction while in the brace. Obliteration of the lumbar lordosis produces compensatory thoracic hyperextension, providing more room for the thoracic vertebral bodies, thus causing a derotation effect. While animal models of idiopathic scoliosis have tended to resist development until recently, there has always been one superb human model. It is critical when fusing a spine for idiopathic scoliosis to do so from neutral vertebra above to neutral vertebra below (Goldstein 1973). Too short a fusion is the most common cause of deterioration of the curve after the operation, sometimes at a greater rate than before (Roaf 1966). This is because the primary lordosis has been augmented by too short a fusion, which acts as a tethering strut facilitating rotational progression.

Current methods of treatment for idiopathic scoliosis are directed entirely towards the secondary deformity. While bracing may at best prevent progression, surgical procedures at best improve the coronal plane curvature component by 50 per cent, with a much less satisfactory correction of the rotational prominence. Elucidation of the pathogenesis of idiopathic scoliosis enables treatment to be directed towards the primary deforming mechanisms, of which the lateral profile is the more important. If the normal thoracic kyphosis is recreated at the apex of the curve in the experimental animal, then the secondary deformity resolves with growth (Dickson $e t$ al. 1983). This can be achieved clinically by lifting the posterior elements of the apical vertebrae back to a normal kyphosis. Without spinal fusion the spine may grow straight and thus biological treatment can be considered.

As with many orthopaedic conditions by the time they achieve clinical significance, it is the secondary deformity which is so obvious and masks or obscures the underlying primary deformity. The lateral curvature of the spine with rotation is secondary. Biplanar spinal asymmetry during growth is the essential lesion.

We acknowledge the invaluable assistance of Messrs Somerville, Berkin, Bliss, Jobbins and Professor Dowson in this study.

\section{REFERENCES}

\footnotetext{
Adams W. Lectures on the pathology and treatment of lateral and other forms of curvature of the spine. London: Churchill and Sons, 1865. Alexander MA, Season EH. Idiopathic scoliosis: an electromyographic study. Arch Phys Med Rehabil 1978;59:314-5.

Boas F. Studies in growth. Hum Biol 1932;4:307-50.

Blount WP, Moe JH. The Milwaukee brace. Baltimore: Williams \& Wilkins, 1973.

Brash JC. Cunningham's text-book of anatomy. 9th ed. London: Oxford University Press, $1951: 3-4$.

Burwell RG, James NJ, Johnson F, Webb JK. The rib hump score : a guide to referral and prognosis? J Bone Joint Surg [Br] $1982 ; 64-B: 248$.

Deane G, Duthie RB. A new projectional look at articulated scoliotic spines. Acta Orthop Scand 1973;44:351-65.

Dickson RA. Scoliosis in the community. Br Med J 1983;286:615-8.

Dickson RA, Lawton JO, Archer IA, et al. Combined median and coronal plane asymmetry: the essential lesion of progressive idiopathic scoliosis. J Bone Joint Surg [Br] 1983;65-B:368.

Dickson RA, Sevitt EA. Growth and idiopathic scoliosis: a longitudinal cohort study. J Bone Joint Surg [Br] 1982;64-B:385.

Goldstein LA. The surgical treatment of idiopathic scoliosis. Clin Orthop 1973;93:131-57.
} 
Gottlieb O. Experimental scolioses (advance report). Acta Orthop Scand 1957;26:295-6.

Hassan I, Bjerkreim I. Progression in idiopathic scoliosis after conservative treatment. Acta Orthop Scand 1983;54:88-90.

Heuer F. Zur Theorie der Scoliose. Hessisches Ärtzteblatt 1927 No. 18 and ff. (Cited by Wittebol P, Idiopathic scoliosis (an experimental investigation). Arch Chir Neerl 1956;8:269-79.)

Inkster RG. Osteology. In: Brash JC, ed. Cunningham's text-book of anatomy. 9th ed. London: Oxford University Press, $1951: 105$.

Kaneko T. Histopathological and histochemical studies on the back muscles in scoliosis. J Japan Orthop Assoc 1968;42:13-28 (in Japanese).

Karaharju EO. Deformation of vertebrae in experimental scoliosis: the course of bone adaptation and modelling in scoliosis with reference to the normal growth of the vertebra. Acta Orthop Scand 1967; Suppl 105.

Khosla S, Tredwell SJ, Day B, Shinn SL, Ovalle WK Jr. An ultrastructural study of multifidus muscle in progressive idiopathic scoliosis: changes resulting from a sarcolemmar defect at the myotendinous junction. J Neurol Sci 1980;46:13-31.

Lerique and Le Coeur. Action potential asymmetry on two sides. 1951. (Cited by Le Febvre J, Triboulet-Chassevant A, Missirliu MF. Electromyographic data in idiopathic scoliosis. Arch Phys Med Rehabil 1961 ;42:710-1.)

Roaf R. The basic anatomy of scoliosis. J Bone Joint Surg [Br] 1966;48-B: 786-92.

Sabatier. Traité complete d'anatomie. Paris, 1777. (Cited by Farkas A. Physiological scoliosis. J Bone Joint Surg 1941;23:607-27.)

Sahlstrand T, Petruson B. A study of labyrinthine function in patients with adolescent idiopathic scoliosis. 1. An electro-nystagmographic study. Acta Orthop Scand 1979;50:759-69.

Somerville EW. Rotational lordosis: the development of the single curve. J Bone Joint Surg [Br] 1952;34-B:421-7.

Sorensen ICH. Scheuermann's juvenile kyphosis. Copenhagen: Munksgaard, 1964.

Sørensen K. Scheuermann's juvenile kyphosis : clinical appearances, radiography, aetiology and prognosis. Copenhagen : Munksgaard, 1964.

Stagnara P, Fleury D, Fauchet R, et al. Scolioses majeures de l'adulte supérieures à 100 degrés: 183 cas traités chirurgicalement. Rev Chir Orthop $1975 ; 61: 101-22$.

Staub HA. Eine skoliotikerfamilie. Ein beitrag zur frage der kongenitalen skoliose and der hereditat der skoliosen. Z Orthop Chir 1922;43:1-20.

Trontelj JV, Pečak F, Dimitrijević MR. Segmental neurophysiological mechanisms in scoliosis. J Bone Joint Surg [Br] 1979;61-B:310-3.

Whittle MW, Evans M. Instrument for measuring the Cobb angle in scoliosis. Lancet 1979; $1: 414$.

Willner S. Spinal pantograph-a non-invasive technique for describing kyphosis and lordosis in the thoraco-lumbar spine. Acta Orthop Scand $1981 ; 52: 525-9$

Wittebol P. Idiopathic scoliosis (an experimental investigation). Arch Chir Neerl 1956;8:269-79.

Wynne-Davies R. Familial scoliosis. In Zorab PA, ed. Proceedings of a symposium on scoliosis: held in the Institute of Diseases of the Chest, The Brompton Hospital, London on 5 and 6 July 1965. Action for the Crippled Child Monograph. London: National Fund for Research into Poliomyelitis and other Crippling Diseases, 1965;36-41.

Yamada K, Takaaki I, Yamamoto H, Nakagawa Y, Tanaka H, Tezuka A. Equilibrium function in scoliosis and active corrective plaster jacket for the treatment. Tokushima J Exp Med 1969;16:1-7. 